\title{
ENHANCED SOLUTIONS FOR COMPLEX ROLLING MILL MODERNIZATION PROJECTS*
}

\begin{abstract}
Once installed rolling mills can look forward to a long life. Around $40 \%$ of the 140 conventional hot strip mills presently in operation were built between 1960 and 1970 . 17 of the 29 CSP $^{\circledR}$-plants were commissioned before the year 2000 and have automation platforms that are obsolete and/or have outdated rolling technology. Keeping pace with the market requirements is an ongoing challenge for producers of flat steel. It is a real balancing act keeping production facilities performing at necessary levels, safeguarding the investment and keeping outage periods to a minimum. To overcome these demanding factors and strike the right balance allowing for the production of higher grade steel that meets the current market price the installation of mechanical equipment as well as automation platforms and process technology must meet the latest technology standards. Being discussed in this paper are the different motives for modernizations along with their impact on project handling and commissioning philosophies. Experience gained during recent modernization projects in the field of flat steel rolling relating to Steckel / plate mills or current $\mathrm{CSP}^{\circledR}$ modernizations will be shared and demonstrate that each modernization has its own individual solution. Specific strategies are explained to help optimize production, increase plant agility and maximize the return on investment.
\end{abstract}

Keywords: Hot strip mill; CSP ${ }^{\circledR}$-plant; Steckel mill; Steckel looper; Super reinforced laminar cooling; Plug \& Work test; Camber-free rolling; CVC ${ }^{\circledR}$; PCFC ${ }^{\circledR}$. 


\section{INTRODUCTION}

"Steel is the raw material of the past" we can read this over and over again. Many sectors are lost to the aluminum market. But is this really valid? E.g. ArcelorMittal has encouraging pro steel news: For example in the car industry lost terrain is being regained by developing high-strength and ultra-high strength steels. From the same source we learn that the new VW Golf consists of $80 \%$ high strength steel compared to $66 \%$ in the previous model. [1]

New steel developments may open new applications in a highly competitive market. Steel producing facilities have to keep pace with the new demands - modernizations appearing on the agenda. This and further motivations will be discussed.

\section{MATERIAL METHODS \& RESULTS}

The Challenge to stay up-to-date

A brand-new rolling mill at start-up when being engineered, manufactured and commissioned by a world-class supplier of roll mill technology would definitely have the state of the art technology and production know-how. However, maintaining the same level throughout is challenging. Staying ahead of the competitors in the highly competitive and at times cannibal steel market after one or two decades of production is a challenge every supplier must face.

Figure 1 shows development of steels in CSP ${ }^{\circledR}$-plants since the first CSP $^{\circledR}$-plant commissioning in 1989. This gives an idea about the gap in technology and production know how between the day of commissioning and years down the road.

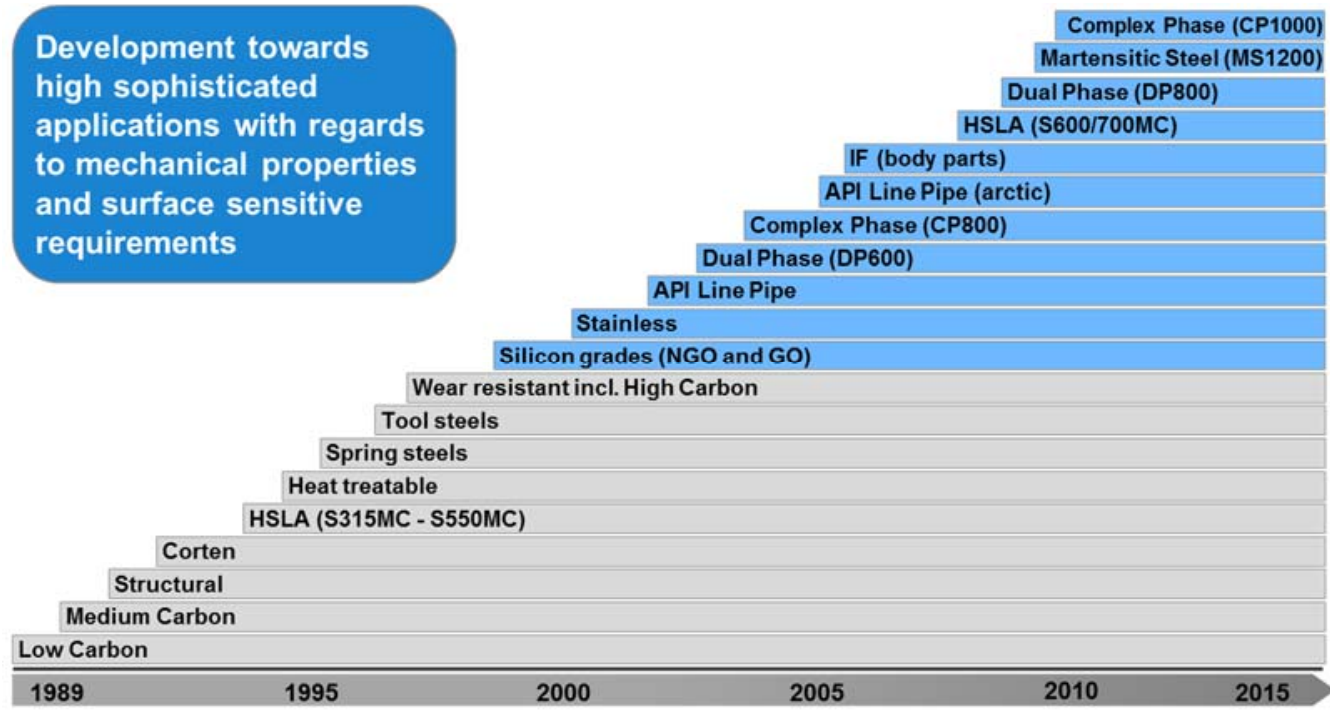

Figure 1: Market introduction of steel grades on CSP ${ }^{\circledR}$-plants since the first CSP ${ }^{\circledR}$ installation in 1989

\section{Motives behind modernization}

There are three main factors for steel producers to modernize their mill:

- Improve product quality

- Widen product portfolio

- Increase production

Besides these motives, secondary motives can also be seen that justify modernizations. Such co-factors are

1. Maintaining plant availability

The life of electrical \& automation systems is limited. The non-availability of major automation or drive components at the end of their life often makes an upgrade or 
complete exchange inevitable. The steel producer has to bear the costs for the new automation or drive systems. Moreover - depending on the project extent - he has to temporarily shut down the production facilities for the modernization activities and loses further. Therefore most steelwork owners are looking at additional benefits from the 3 main motives mentioned above to utilize shutdown periods to a maximum possible extent.

\section{Increase efficiency}

Example: In the 1990's the first choice for hot strip mill main drives was to install cyclo-converter driven synchronous motors at a voltage level of typically around 1300V. Due to their design these drives caused the need to also foresee compensation systems: filter circuits reduce the negative influence of the main drives like harmonic distortion and poor power factor, a dynamic compensation (thyristor controlled reactors) was installed to reduce the negative influence of the drives. Maintaining these passive and active filters is a costly affair and money is lost with each used kW. Estimates show that the electrical losses are in a range of $2 \%$. Modern active front-end converter systems that run on a voltage level above $3 \mathrm{kV}$ do not require costly filter circuits. Steel producers will every once in a while evaluate the exchange of old drive systems against new ones. However, exchanging obsolete drive systems is costly as well as requiring a mill shutdown for several weeks. Therefore, mentioned before, a stand-alone modernization of the drives would in most cases not be considered as steel producers would always look for additional gain from at least one of the three main factors.

\section{Cost reductions}

Steel plant owners likewise continuously check their whole production process in order to identify the possibility for cost savings. Modernizing the cooling equipment, like introducing super reinforced cooling groups behind the finishing mill could be one option. Doing so would help reducing costly alloy elements. Depending on the production rate and product portfolio savings of 2 US\$ per t of micro-alloyed steels are in a realistic range.

Another advantage of using super reinforced cooling would be the production of high strength grades with lower chemistries. [2]

Figure 2 shows the effect of decreased grain size on the properties. Yield strength, tensile strength and elongation are significantly improved by the introduction of 4 super reinforced laminar cooling groups in a CSP ${ }^{\circledR}$-plant in the US.

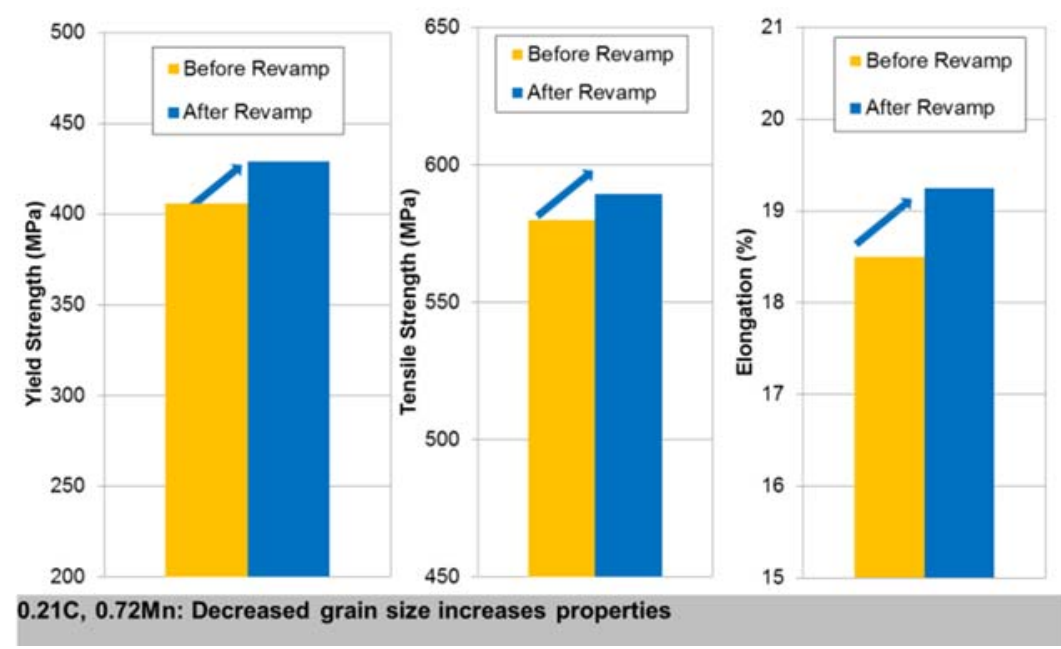

Figure 2: CSP${ }^{\circledR}$-plant modernization; effect of new super reinforced cooling equipment 
4. Legal obligations

National authorities may implement new safety standards that may require modernizations in installed mechanical and electrical and automation equipment. Whether these activities may require down times parallel utilization for improvements will most likely be evaluated.

For suppliers it is mandatory to work in all fields: the 3 main factors and in the cofactors and to offer the steel industry suitable solutions.

\section{Improve Product Quality}

Flat steel products have to be produced within tight tolerances. The market demands have increased significantly. Steel producers have to acknowledge this to receive premium pay for their products or to remain in the market at all.

Since 1966, ThyssenKrupp Steel Europe has produced a highly demanding range of strips made of carbon and special steels at its Bochum plant in Germany comprising of

- 4 reheating furnaces (1PTF, 3WBF)

- 14 hi roughing stand including edger

- Coilbox

- 7 finishing mill stands

- Laminar cooling section

- 3 universal down coilers

To further improve the quality of hot strip, the company modernized in a first step the roughing train of the plant including the automation in 2010. This installation included a new heavy edger (refer to figure 3 ) and the renewal of the complete roughing mill automation system. [3]

The new edger has the following technical data:

Diameter of edging rolls max. $1,100 \mathrm{~mm}$

min. $1,000 \mathrm{~mm}$

Edger opening during operation 600 to $2,000 \mathrm{~m}$

Total rolling force up to $8,500 \mathrm{kN}$

Rolling Speed up to $7 \mathrm{~m} / \mathrm{s}$

Pass reduction up to $100 \mathrm{~mm}$

Rated drive power $\quad 2 \times 2,000 \mathrm{~kW}$

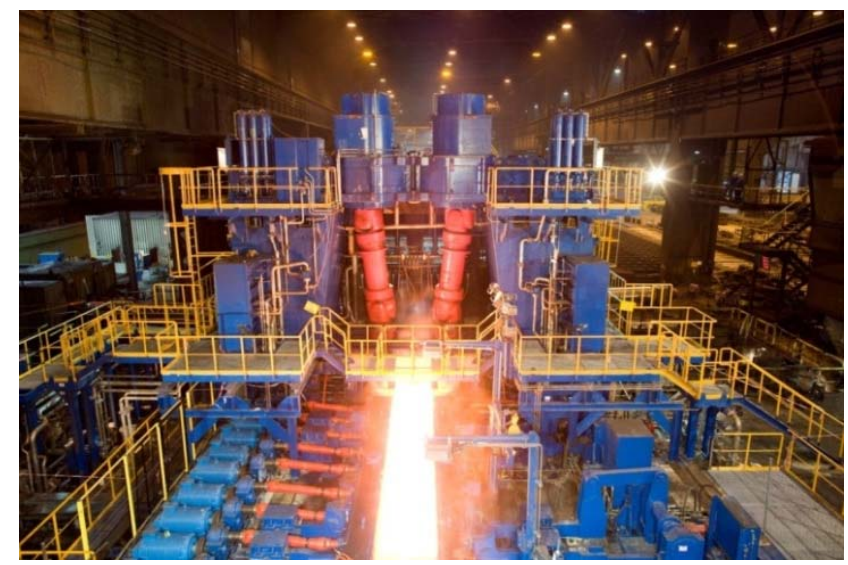

Figure 3: ThyssenKrupp Steel Bochum - new edger in operation 
SMS Group has replaced the complete old automation system of the roughing train including the process model for an optimal pass schedule structure and the width setup being an essential part. Moreover, the Automatic Width Control (AWC) provides a constant transfer bar width and the Short Stroke Control (SSC) minimizes the cropping losses on the head and tail end of the transfer bar.

Furthermore, SMS Group's proven Camber Free Rolling (CFR) system was introduced at ThyssenKrupp Bochum. Together with heavy side guides and the specially developed roll alignment control it allows production of practically camber and wedge-free transfer bars in the roughing mill as shown in figure 4 . Costs saving benefits were achieved thru increased yield, improved strip geometry due to camber and wedge reduced to minimum and improved process stability thanks to better strip guidance.
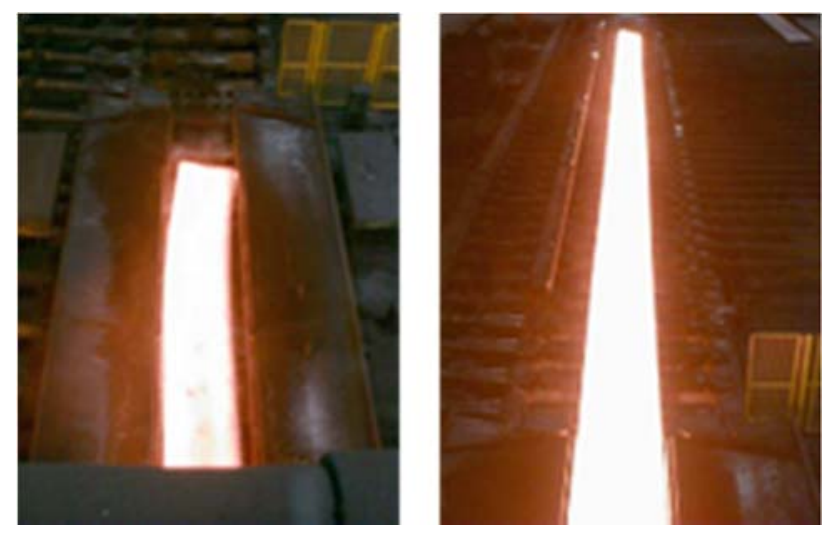

Figure 4: Impact of camber free rolling on the transfer bar behind the roughing stand - left after $1^{\text {st }}$ pass, right after $5^{\text {th }}$ pass

\section{Results}

Thanks to the modernization, the geometric tolerances of the transfer bar could be enhanced and particularly transfer bar cambering could be prevented. Thus, the stability of the rolling process in the finishing train was improved. The edger attached to the horizontal stand along with the new sequence control system enable shorter reversing times and optimized operating cycles. This significantly improved the productivity of the roughing mill.

Regarding the main focus of improving product quality for all material classes a significant improvement in the quality of product's width could be observed - as shown in figure 5. 


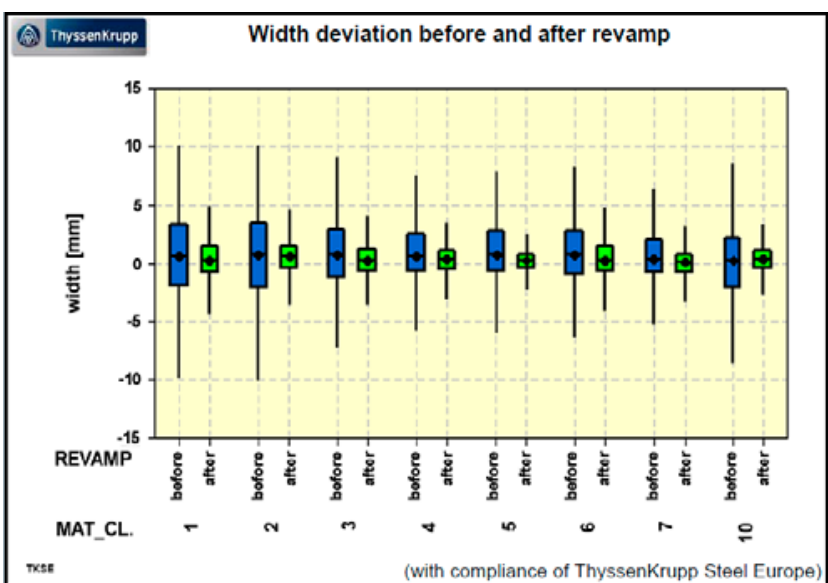

Figure 5: ThyssenKrupp Steel Bochum -width improvement results for different material classes

Additionally, the new roughing mill process automation system includes a new pacing control to optimally utilize the capacity of the hot strip mill. Regarding the mechanical equipment, SMS Group also supplied the drives, new hydraulic side guides and work roller tables in the roughing stand area in addition to the edger itself. Furthermore, key components in the four-high reversing stand were renewed.

\section{Concept for short plant downtimes}

For this modernization, SMS Group developed a reconstruction concept combining the mechanical equipment with the $\mathrm{X}-\mathrm{Pact}^{\circledR}$ electrics and automation. The new edger was assembled during continuous operation next to the rolling line and regular maintenance shutdowns were used to carry out partial assemblies on the horizontal stand. During a major shutdown the old free-standing edger was dismantled. The complete new unit could be advanced to the final position by means of a transporting system and flanged to the roughing stand.

For the replacement of the automation, an innovative method which significantly reduced the downtimes was utilized. This ensured ongoing production and accelerated the commissioning. The basis for this is a Process-IO-Server (PIOS) which was installed in customer's plant during scheduled plant downtimes. Owing to this automation "centerpiece", a type of electronic terminal strip with software switch, the shadow mode and a gradual switching to the new signal paths of the new automation could be performed.

Before delivery, SMS Group had already tuned the new automation of the roughing train to the customer's plant specifications with the aid of the Plug \& Work procedure.

\section{Finishing mill and cooling section}

After the successful modernization of the roughing train, SMS Group was given the order for modernizing the finishing train and the laminar cooling system of the hot strip mill at ThyssenKrupp Steel Europe in Bochum.

Widen product portfolio 
The trend in hot rolling in the last few years has moved towards producing highstrength steel and advanced steel grades with superior strip quality. HSLA, DP, Multiphase, API, silicon steel (NGO and GO) to name a few.

SSAB e.g. further developed their special product Hardox ${ }^{\circledR}$ - a wear-resistant steel plate material. For this reason they invested more than 150 million $€$ to enable their hot strip mill in Borlänge, Sweden originally set into operation back in 1961.

Target was to produce high strength steel with a tensile strength in excess of 1,100 $\mathrm{MPa}$ and direct quenched (DQ) hot band in the thickness range of up to $8 \mathrm{~mm}$. [4]

First SSAB installed 2 new down coilers out of which the down coiler \#4 was put into operation in the summer of 2008 and the down coiler \#5 commenced its operation in the autumn of 2010 . Both new down coilers can wind high strength steel (1.100 MPa) up to $8 \mathrm{~mm}$ and mild steel up to $15.4 \mathrm{~mm}$. Also in autumn of 2010 a new walking beam conveyor with horizontal axis and a new in-line inspections station for samples up to $7 \mathrm{~m}$ for both sides were installed.

Finally in the summer of 2011 the revamp was completed with the following:

- New Run-Out Table with laminar cooling

- 11 zones with 6 valves ( 2 headers per valve)

- 1 zone with 12 valves ( 1 per header)

- New water treatment plant $\left(15,500 \mathrm{~m}^{3} / \mathrm{h}\right)$

- New Level 2 setup models on a physicalmathematical basis:

- Pass Schedule Model PSC ${ }^{\circledR}$ for setup and microstructure evolution

- Profile Contour and Flatness Model PCFC ${ }^{\circledR}$ for setting of $C V C^{\circledR}$ shifting and work roll bending

- Cooling Line Model CSC ${ }^{\circledR}$ describes the microstructure as a function of the chemical composition at different temperatures and cooling rates

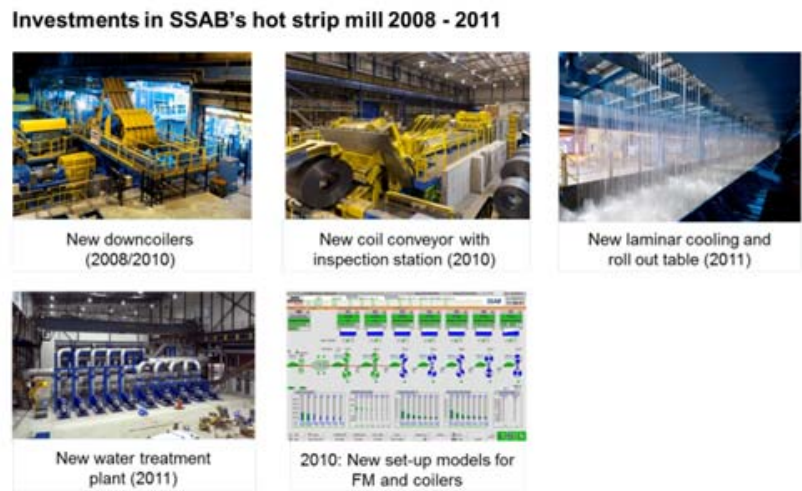

Figure 6: Major Investments of SSAB from 2008 - 2011

Figure 6 shows an overview about the modernized plant areas.

Three weeks after start-up of the new laminar cooling line SSAB produced their first Hardox ${ }^{\circledR}$ requiring coiling temperature of approximately $100^{\circ} \mathrm{C}$.

During 2012 SSAB produced Hardox ${ }^{\circledR} 400$ and 450 and was able to establish these products in the market.

At the same time with the new finishing mill set-up models in operation the performance of the hot strip mill was improved further. 


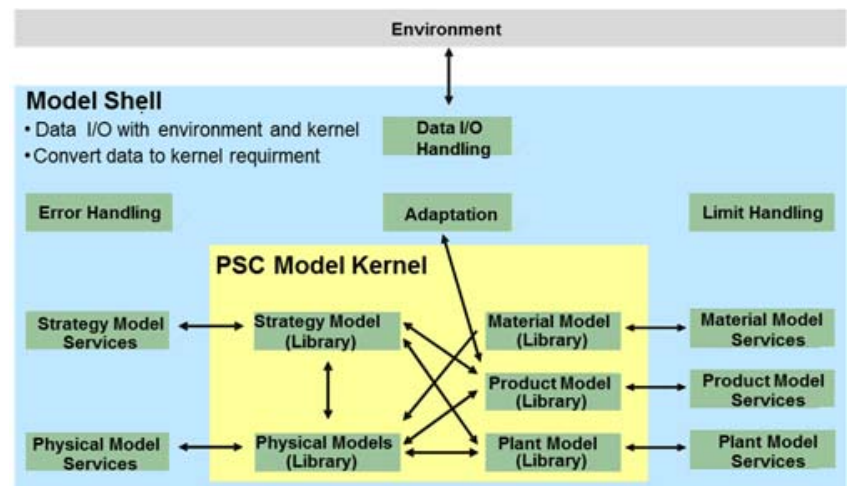

Figure 7: Layout of the new set-up model for the finishing mill

With the newly installed Level 2 setup models on a physical-mathematical basis (figure 7) the thickness and coiling temperature results could drastically be improved. Figure 8 and 9 show these results.

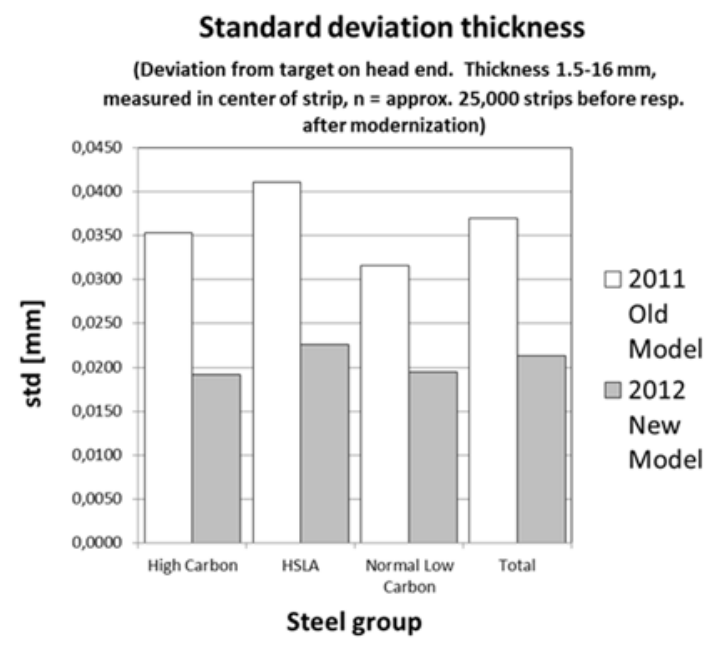

Figure 8: Operational results for head end thickness performance

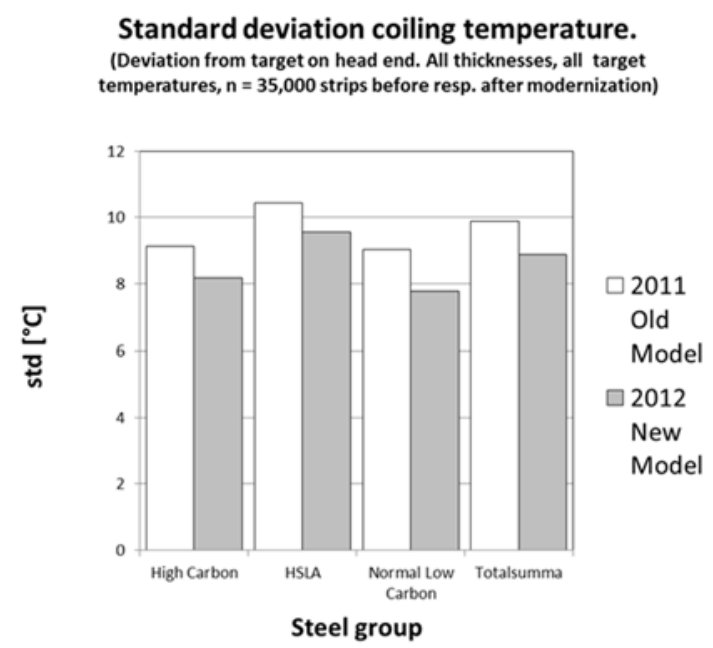

Figure 9: Operational results for coiling temperature performance 
In the example shown above, SSAB reached their main target of widening their product portfolio; product and dimension range for high strength steels (DQ and HSLA) are now extended. Their Hardox ${ }^{\circledR}$ wear plate program now covers the thickness range from 0.7 to $130 \mathrm{~mm}$. Their quality parameters for thickness and coiling temperature also improved. And last but not least, with the installed Level 2 setup models SSAB is able to easily further develop new products and dimensions.

\section{Increase Production}

The Shandong Taishan Group Co. Ltd., located in Laiwu City of the Shandong province is a Chinese steel producer with a capacity of five million tons of low carbon steel and stainless steel. Their product range includes steel for machinery, automobiles, home appliances, petrochemical and construction.

In 2012 Shandong Taishan decided to extend the plant's production rate from $600,000 \mathrm{t} / \mathrm{a}$ to $1,8000,000 \mathrm{t} / \mathrm{a}$ by adding 3 finishing mill stands and 1 down coiler to their $1+1$ roughing mill / Steckel mill installation. Their main products are stainless steels.

Along with the originally installed $1,800 \mathrm{~mm}$ roughing mill and Steckel mill stands, Shandong Taishan intended to further install the 3 finishing mill stands in place of the laminar cooling line. The laminar cooling line would have been shifted at its original length but that would have meant that the installed coiler too had to be shifted. Moreover, an additional coiler 2 had to be installed behind coiler 1.

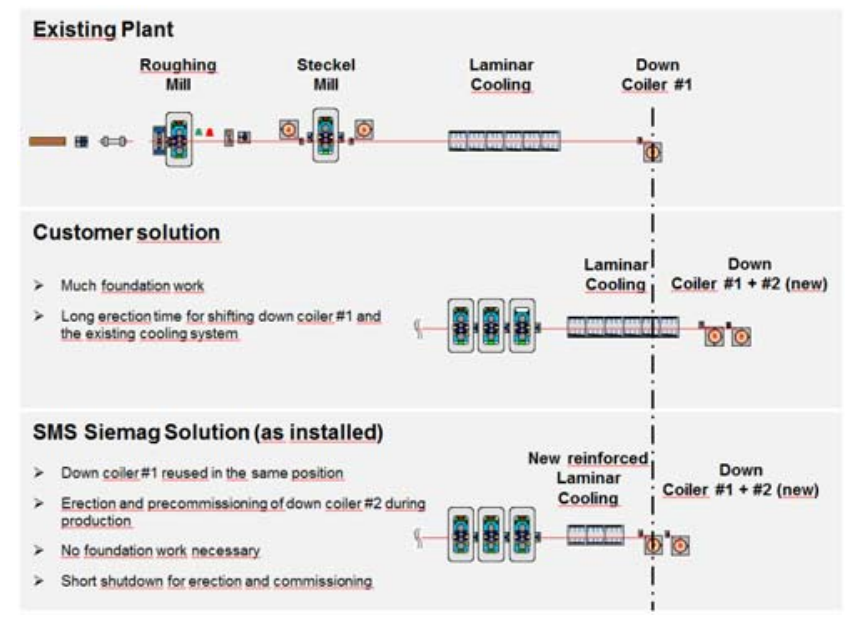

Figure 10: original layout RM/Steckel mill stand - original revamp strategy - realized revamp layout

SMS Group suggested a different solution: When shortening the cooling section by introducing a reinforced cooling line the coiler 1 could stay at its original position (figure 10). This could help significantly reducing the shutdown activities and costs. Shandong Taishan was immediately convinced and decided in favor of this solution.

Besides enhancing the plant's production rate up to 1,800,000 t/a by adding 3 FMs and 1 DC Shandong Taishan had the following targets:

- Achieve reproducible, fully automatic and reliable rolling process

- Achieve reproducible product quality based on latest rolling technology

- Minimize installation and commissioning risks involved in the revamp project

- Energy savings, increase productivity and lower productions costs 
For this plant modernization SMS Group mainly supplied

- Complete new Level 1 and Level 2 automation systems for the complete mill, i.e. for the existing roughing and Steckel stand, for the three new finishing stands, the new reinforced laminar cooling, for the existing coiler \#1 and for the new coiler \#2.

- New main drive equipment for the new installations

- New CVC ${ }^{\circledR}$ plus work roll shifting systems and bending system for the Steckel mill

- $\quad$ New PCFC ${ }^{\circledR}$ process models

- $\quad$ Steckel looper pinch roll unit

- New reinforced laminar cooling system

\section{Results}

With the recommended procedure of replacing the existing laminar cooling section with a reinforced cooling section, coiler \#1 could stay at its original position. This not only saved installation costs but also contributed to a 33 days reduction in the overall planned shutdown period to a total of 48 days only.

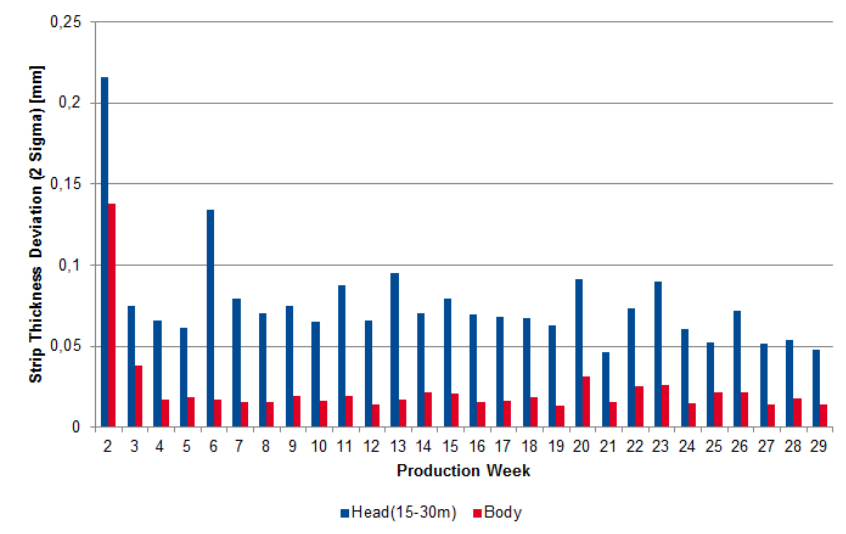

Figure 11: Thickness results for strip head body - 2 sigma values in [mm]

The geometrical strip quality is excellent after the installation and is far beyond Shandong Taishan's expectations. Figure 11 shows the thickness deviations for strip head and body. The thickness deviation for the body is within $0.015 \mathrm{~mm}$. After final tuning the thickness deviation is close to conventional hot strip mills. The full contractual productions scope was already reached within 4 weeks after production restarted as shown in figure 12.
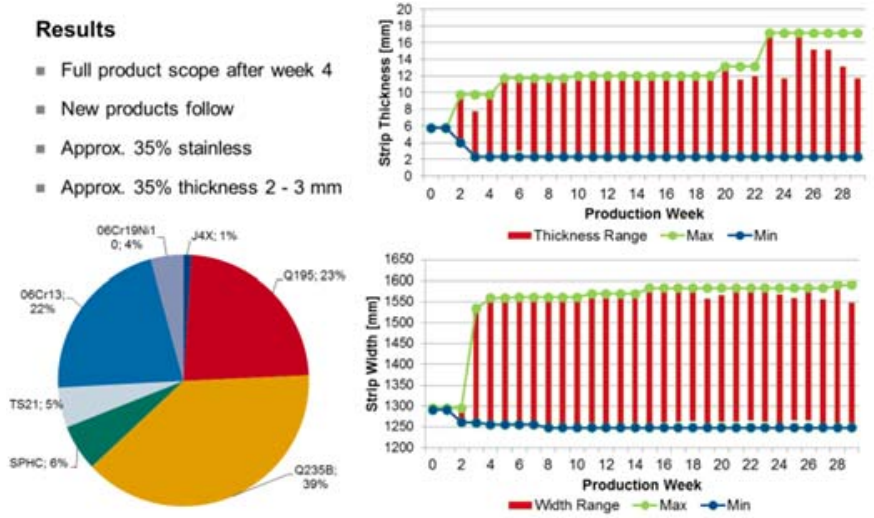

Figure 12: Thickness and width production - full contractual production scope 4 weeks after mill restart 
Drum slot overlaps in the Steckel mill process cause sharp diameter changes in the hot coil. These sharp diameter changes cause tension fluctuations in the strip that can be seen as a thickness deviation in the strip. Another negative influence can be observed on strip centerline deviations that result in a high cobble risk.

The patented SMS Group Steckel looper pinch roll unit (figure 13) installed between the Steckel mill stand and the Steckel coiler helps keep the tension between stand and drum constant. This is realized by a proven control strategy implemented in the automation control system. This on one hand helped to improve the thickness performance and on the other to stabilize the rolling process that can be observed in a significantly reduced cobble rate close to zero. By installing the Steckel looper pinch roll unit the rolling speed can even be increased up to $20 \%$. Figure 14 shows the impact of the Steckel looper on the thickness performance.

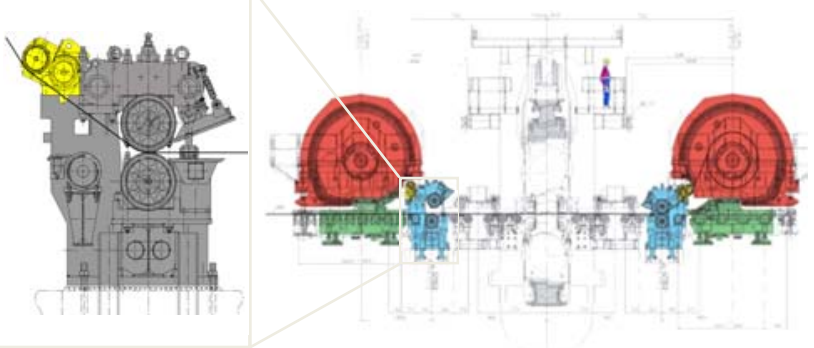

Figure 13: Mechanical drawing showing the Steckel looper pinch roll unit between Steckel mill stand and Steckel coiler

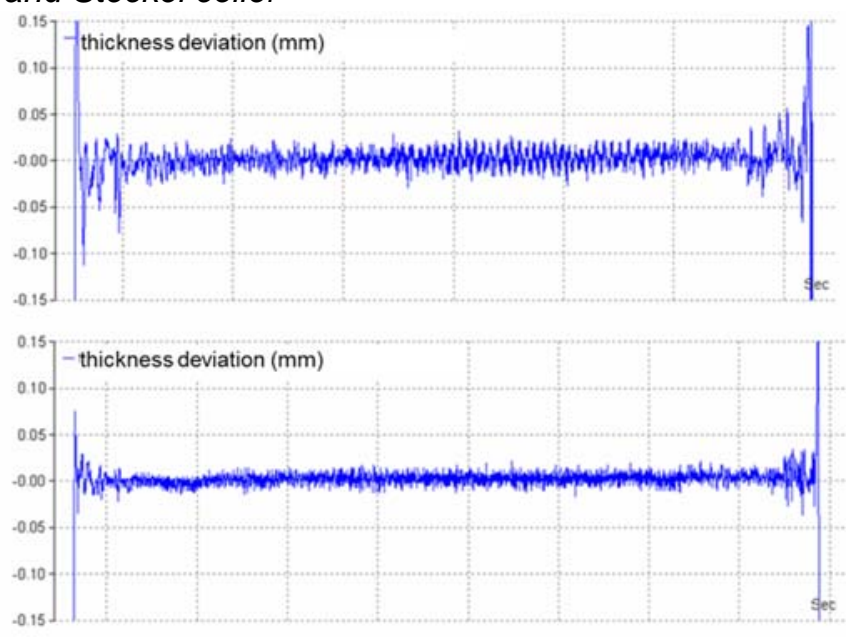

Figure 14: Impact of Steckel looper on strip thickness: upper chart shows strip thickness without and bottom chart with active Steckel looper

\section{Essential Considerations}

Once the decision is made for the modernization, impacts on mechanics, process and electrics \& automation have to be thoroughly evaluated - the whole modernization concept has to be developed. With the focus on electrics \& automation, the brains and muscles of the plant - the steps should be as follows:

\section{Fact-finding}

Major mill modernizations will always target for mill performance towards the current state-of-the art. The equipment has to perform accordingly. Therefore the actual status and every detail have to be investigated. The major fields for evaluations are: 
- The current status of the sensors and technological measurement systems (e.g. for thickness, profile and flatness)

- The drive train including main motors, gear boxes, spindles and pinion units, recording of step responses

- The hydraulic systems including valve stands for mill and coiler; control behavior of the respective technological control circuits including recording of step responses

- Respective alignment and functions of descaler, roll cooling, interstand cooling, anti-peeling and roll gap lubrication systems

- Mill stand windows and chocks including their alignment

- Grease lubrication systems

- The laminar cooling section regarding alignment, status of headers, reproducibility

Critical controls step responses and friction measurements should be recorded well in advance. This helps during later clarifications.

Regarding automation, the focus of the current systems and their communication to retained systems has to be carefully investigated and documented. Target should be an updated motors- and components list for the respective modernization areas.

The current plant operation using its Standard Operational Procedures (SOPs) must be understood, documented and discussed with the plant's operational and maintenance personnel. Using this basis, the new SOPs are developed and coordinated with the people working every day in the plant.

\section{Detailed planning}

The modernization projects realized in multiple phases or in a single shot have to be planned in detail, considering mechanical, process and electrics \& automation aspects along with current production requirements. By ensuring a high parallelization of the necessary work operations before, during and after production stoppages, a shortest possible shutdown period is achieved. Based on previously defined milestones, the sequence of each shutdown is monitored by competent and well net-worked site managers and revised if necessary.

\section{Plant test}

For the automation the results of the findings are incorporated into the hardware and software engineering. Following SMS Group's Plug \& Work concept of SMS Group, the engineering process comes to its successful end with testing of the complete automation system against a separate real-time simulation of the process. This is done to an extent that the actual automation system is unaware that it is connected to a highly sophisticated simulation system instead of the real plant. The Simulation reproduces dynamics, kinematics and technological processes of the plant with an amazing level of detail. 


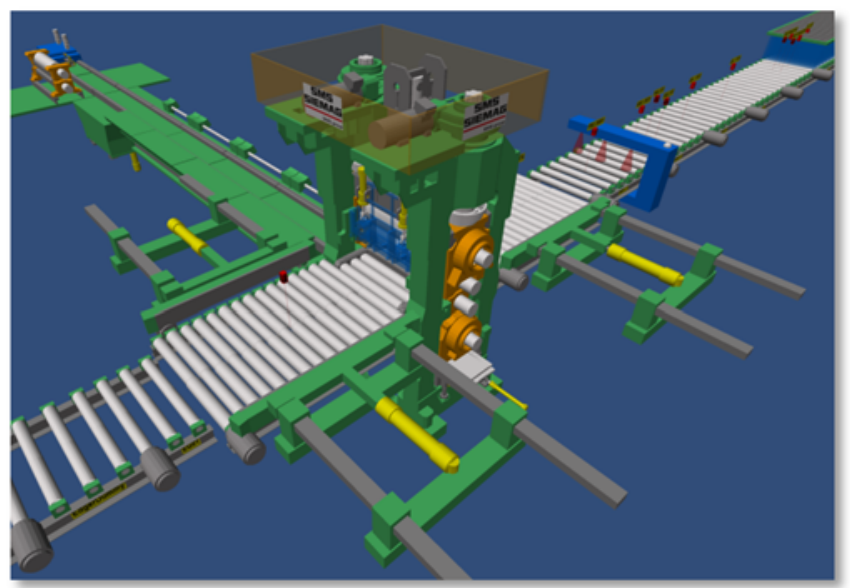

Figure 15: 3D plant visualization in SMS Group's Plug \& Work Test for process and production simulation

Figure 15 shows an example of a plate mill stand with its customer specific features. The process and simulation visualization in the Plug \& Work test area is accessible for the whole test team (figure 16).

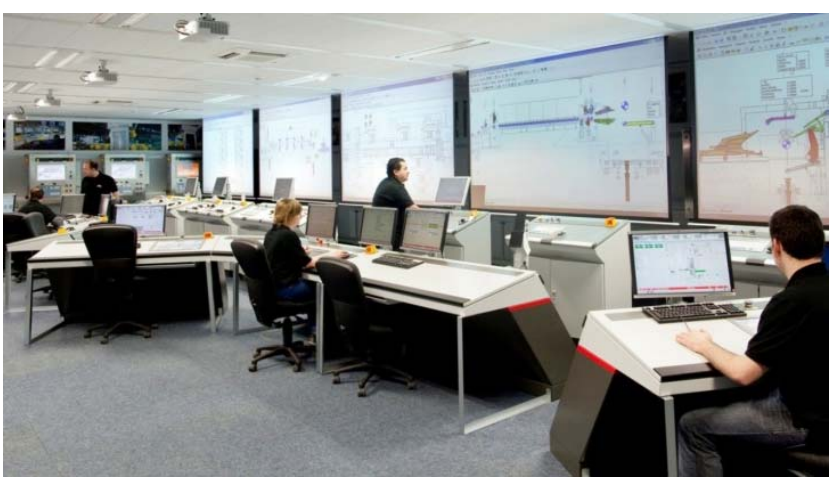

Figure 16: Plug \& Work Test: original automation equipment including operation desks and stations in the test field

The vision is to supply to site, fault-free packages, systems, communications and pre-optimized technological solutions. With using original mechanical drawings as a basic input for the simulation, interaction between mechanics and automation can already be tested in the test field. Finally, operation and maintenance personnel can be trained under near-real conditions well ahead the shutdown.

The results are obvious: shorter commissioning times, rapid start-ups and a confident take-over of a reliable plant to a well-trained staff.

\section{CONCLUSIONS}

The overcapacity in the world's steel production tells us that new plants will only be built to a limited extent. Steel producers will more thoroughly check their existing facilities and investigate modernization scenarios to suit their strategic positioning in the market.

As outlined in the examples there is not a general advice that suits all steel suppliers as in how to keep one's production facilities up to date. Each supplier has to develop his own strategy and define in which way to move. But once the decision is made for 
a modernization, it is prudent to have an experienced partner by your side whose daily business is to handle complex modernization projects in the steel industry.

\section{REFERENCES}

[1] Wocher, M.; Murphy, M.: Die Zeit der Entrostung - Wie Europas Stahlbranche ihre Krise überwinden will; Handelsblatt 27.02.2015

[2] Krämer, S.; Sprock, A.; Hassel, C.: Efficient strip cooling to meet requirements of advanced steel grades; Stahl und Eisen 133 (2013) Nr. 10

[3] Newsletter of the SMS Group 1/2011: New edger with optimal automation for the hot strip mill

[4] Thurgren, M.; Högberg, R.; Johansson, E.; Sixtensson, P.; Eckelsbach, K.; Metz, $\mathrm{H}$.; Wagener, M.: Striving for ultra high-strength and direct-quenched hot band.

Modernization of SSAB's hot strip mill; JSI Paris 18-19 December 2012 